\title{
Relationship between Physicochemical Characteristics and Pathogenic Leptospira in Urban Slum Waters
}

\author{
Daiana de Oliveira ${ }^{1,+} \oplus$, Vladimir Airam Querino ${ }^{2, \dagger}{ }^{\text {, Yeonsoo Sara Lee }}{ }^{3,4} \mathbb{C}^{\circ}$, Marcelo Cunha ${ }^{5}$, \\ Nivison Nery, Jr. ${ }^{1,4}$, Louisa Wessels Perelo ${ }^{2}$, Juan Carlos Rossi Alva ${ }^{6}$, Albert I. Ko ${ }^{1,7}$, \\ Mitermayer G. Reis ${ }^{1,7,8}$, Arnau Casanovas-Massana ${ }^{7, *,+}+\mathbb{C}$ and Federico Costa $1,4,7, *,+$
}

1 Instituto Gonçalo Moniz, Fundação Oswaldo Cruz, Ministério da Saúde, Rua Waldemar Falcão, 121, Candeal, Salvador CEP 40296-710, Bahia, Brazil; daisoliveira@hotmail.com (D.d.O.); nivison.nery@conveniado.bahia.fiocruz.br (N.N.J.); albert.ko@yale.edu (A.I.K.); mitermayer.reis@fiocruz.br (M.G.R.)

2 Department of Environmental Engineering, Escola Politécnica, Universidade Federal da Bahia, Rua Aristides Novis, 02, Federação, Salvador CEP 40210-630, Bahia, Brazil; vlaairam@yahoo.com.br (V.A.Q.); louperelo@gmail.com (L.W.P.)

3 Mayo Clinic Alix School of Medicine, Mayo Clinic, 13400 E. Shea Blvd, Scottsdale, AZ 85259, USA; ysaralee@gmail.com

4 Instituto da Saúde Coletiva, Universidade Federal da Bahia, Rua Basílio da Gama, 316, Canela, Salvador CEP 40110-040, Bahia, Brazil

5 National School of Public Health, Fundação Oswaldo Cruz, Rua Leopoldo Bulhões, 1480-Manguinhos, Rio de Janeiro 05407-002, RJ, Brazil; cunha.ensp@gmail.com

6 Universidade Católica do Salvador, Av. Prof. Pinto de Aguiar, 2589-Pituaçu, Salvador CEP 41740-090, Bahia, Brazil; jcrossiconsult@gmail.com

7 Department of Epidemiology of Microbial Diseases, Yale School of Public Health, 60 College St, New Haven, CT 06510, USA

8 Faculdade de Medicina, Universidade Federal da Bahia, Praça XV de novembro, s/n-Largo do Terreiro de Jesus, Salvador CEP 40026-010, Bahia, Brazil

* Correspondence: acasanovasmassana@gmail.com (A.C.-M.); federico.costa@ufba.br (F.C.)

+ These authors equally contributed to this study.

Received: 14 August 2020; Accepted: 15 September 2020; Published: 16 September 2020

\begin{abstract}
Leptospirosis, a zoonosis caused by pathogenic Leptospira, primarily affects tropical, developing regions, especially communities without adequate sanitation. Outbreaks of leptospirosis have been linked with the presence of pathogenic Leptospira in water. In this study, we measured the physicochemical characteristics (temperature, $\mathrm{pH}$, salinity, turbidity, electrical conductivity, and total dissolved solids (TDS)) of surface waters from an urban slum in Salvador, Brazil, and analyzed their associations with the presence and concentration of pathogenic Leptospira reported previously. We built logistic and linear regression models to determine the strength of association between physicochemical parameters and the presence and concentration of Leptospira. We found that salinity, TDS, $\mathrm{pH}$, and type of water were strongly associated with the presence of Leptospira. In contrast, only $\mathrm{pH}$ was associated with the concentration of the pathogen in water. The study of physico-chemical markers can contribute to a better understanding of the occurrence of Leptospira in water and to the identification of sources of risk in urban slum environments.
\end{abstract}

Keywords: leptospirosis; environmental; sewer; standing; LipL32; pH; salinity; TDS 


\section{Introduction}

Leptospirosis is a zoonotic disease with global distribution that has emerged as a health problem in urban slum communities in tropical and developing countries [1], causing over 1 million cases and almost 60,000 deaths every year [2]. The disease includes a range of manifestations: from a sub-clinical illness or mild influenza-like symptoms to severe complications, such as Weil's disease and pulmonary hemorrhagic syndrome, for which mortality rates are $10 \%$ and $50 \%$, respectively [3]. Leptospirosis is caused by pathogenic spirochetes of the genus Leptospira. Pathogenic Leptospira colonize the kidneys of domestic and wild mammals, notably in rodents who act as chronic carriers, and shed the pathogen in urine [3]. Human infection occurs through contact with infected animal urine or soil and water contaminated with pathogenic Leptospira [4]. Therefore, the environment plays a central role in the spillover infections from animals to humans.

Outbreaks of leptospirosis and endemic transmission have been linked with the presence of pathogenic Leptospira in water [5]. Consequently, research on the environmental phase of the pathogen is of epidemiological importance, especially to unravel the dynamics of transmission. Physicochemical variables such as temperature, salinity, turbidity, and total dissolved solids (TDS) have been associated with Leptospira presence in aquatic environments and survival under laboratory-controlled conditions [6-10]. In general, slightly alkaline waters and high turbidity favor the survival of the bacterium $[9,10]$. However, little is known about the relationship between water physico-chemical variables and Leptospira under field conditions. Specifically, there is a lack of information from waters from urban slums, where leptospirosis is endemic and large outbreaks are reported annually [11-13]. In these settings, the lack of sanitary infrastructure and high rates of rat infestation increase human exposure to contaminated environments [14]. In this study, we aimed (i) to investigate the physicochemical parameters of the surface waters (sewage and standing water) from an urban slum in Brazil and (ii) to evaluate the association between these physico-chemical parameters and type of water and the presence and concentration of pathogenic Leptospira.

\section{Materials and Methods}

This study was performed in Pau da Lima, Salvador, Brazil, a well characterized urban slum community, with precarious housing, poverty, high population density, trash accumulation, and lack of sanitary and sewer infrastructure. A study previously conducted in this neighborhood revealed high leptospirosis infection rates, with 37.8 cases per 1000 inhabitants [15].

We analyzed sewage and standing water samples collected in a previous study which aimed to characterize the spatio-temporal distribution of pathogenic Leptospira [16] in order to evaluate associations with physicochemical characteristics. Samples were collected from 14 sampling sites distributed across an open sewer that flows from the top to the bottom of one of the valleys. Four samples were collected at each site, two from the open sewer and two from standing water located close to the sewer. Sewage was defined as a continuous and open channel that carries household wastewater and rain. Standing water was defined as any body of water accumulated at ground level, with no connection to sewage or other running water, located at up to $10 \mathrm{~m}$ from the sewer. Samples were collected in the morning and afternoon of the same day, for three non-consecutive days during one week in July 2011 and one week in January 2012. Duplicate aliquots of $50 \mathrm{~mL}$ of sewage and standing water were collected in sterile containers using aseptic techniques and processed within $6 \mathrm{~h}$ after collection. One aliquot was used to determine the concentration of Leptospira DNA using a Real-time quantitative-PCR (qPCR) targeting the lipL32 gene. The methods and results for the molecular quantification were published previously [16]. The second aliquot was used to measure physiochemical parameters following standard procedures [17]. Temperature was measured in situ before sample collection. $\mathrm{pH}$ was determined with a digital $\mathrm{pH}$ meter (inoLab) and turbidity using a spectrophotometer (Hach Lange). Salinity, electric conductivity, and total dissolved solids (TDS) were measured using a multiparameter probe (Tetracon 325). The physico-chemical parameters measured here were combined with the previously reported results on Leptospira concentration [16] for subsequent statistical analyses and modeling in combination. 
Averages and standard deviations of physicochemical variables (temperature, $\mathrm{pH}$, turbidity, TDS, salinity, and electric conductivity) were calculated for qPCR positive and negative samples and stratified by water type. The geometric mean and range of Leptospira concentrations were calculated for positive samples. Multiple logistic and linear regressions were used to investigate the relationship between water physicochemical parameters and the presence and concentration of pathogenic Leptospira. The results obtained for each sample were grouped by type of sample (sewage or standing water) for the regression analyses. To select the best model, physicochemical variables were iteratively included to examine individual effects. The parameters that presented a value of $p<0.20$ were included in the multivariate model. The best models were selected based on the lowest Akaike Information Criterion (AIC) value. The final adjusted logistic and linear models accounted for multicollinearity and interaction between variables. All analyses were performed using RStudio v 1.2.5033 [18].

\section{Results}

A total of 284 water samples (166 samples of sewage and 118 standing water) were collected (Supplementary Table S1). Mean temperature, $\mathrm{pH}$, TDS, electrical conductivity, and salinity were different between water samples that contained pathogenic Leptospira and negative water samples (Table 1). Turbidity was the only parameter that did not show a significant difference between positive and negative water samples. Average $\mathrm{pH}$ was 7.1 for positive water samples versus 7.3 negative water samples $(p=0.02)$. Mean turbidity was slightly higher in positive samples, while temperature, TDS, salinity, and water conductivity were higher in negative samples $(p<0.05)$ (Table 1). In an additional analysis (Supplementary Table S2), we observed that there was a significant difference in the all physicochemical characteristics by water type $(p<0.05)$. Mean $\mathrm{pH}$ was 7.3 in sewage samples versus 7.1 in standing water samples. Mean TDS and salinity were higher in sewage samples than in standing water samples (652 versus $359 \mathrm{mg} / \mathrm{L}$ and 0.37 versus $0.12 \%$, respectively).

Table 1. Physicochemical parameters (mean, standard deviation, and p-value) of pathogenic Leptospira positive and negative samples measured in the water samples collected in Pau da Lima.

\begin{tabular}{ccccc}
\hline Physicochemical Parameters & Overall & Positive & Negative & $p$ \\
\hline Temperature $\left({ }^{\circ} \mathrm{C}\right)$ & $25.7 \pm 2.35$ & $25.3 \pm 2.44$ & $26 \pm 2.27$ & $<0.01$ \\
$\mathrm{pH}$ & $7.2 \pm 0.61$ & $7.1 \pm 0.60$ & $7.3 \pm 0.61$ & 0.02 \\
Turbidity (NTU) & $325 \pm 284$ & $352 \pm 292$ & $310 \pm 279$ & 0.23 \\
Total dissolved solids (TDS) & $533 \pm 281$ & $436 \pm 209$ & $592 \pm 302$ & $<0.01$ \\
$(\mathrm{mg} / \mathrm{L})$ & $0.28 \pm 0.306$ & $0.24 \pm 0.35$ & $0.30 \pm 0.27$ & 0.01 \\
Salinity $(\% \mathrm{o})$ & $0.99 \pm 0.55$ & $0.92 \pm 0.60$ & $1.04 \pm 0.50$ & 0.01 \\
\hline Electrical conductivity $(\mu \mathrm{S})$ & & & &
\end{tabular}

The analysis of the parameters included in the final logistic and linear models (odds ratios and coefficients, respectively) is presented in Table 2. The univariate logistic model for the presence of pathogenic Leptospira showed that temperature, $\mathrm{pH}$, TDS, salinity, and conductivity were all significant parameters (Supplementary Table S3). Salinity and electrical conductivity presented high correlation (0.94), with only salinity remaining in the final model. In the final multivariate model, shown in Table 2, only TDS and salinity were significant ( $\mathrm{OR}=0.99, p<0.001$ and $\mathrm{OR}=10.1, p<0.05$, respectively). The increase in one percentage unit of salinity is associated with a 10 times increase in the chance of finding Leptospira when adjusted with TDS (Table 2 and Figure 1B). In addition, the final model included two significant interaction terms: $\mathrm{pH}$ and type of water, and TDS and type of water. The analysis of the interaction between $\mathrm{pH}$ and type of water showed that sewage samples with high $\mathrm{pH}$ had a $25 \%$ reduction in the chance of detecting presence of Leptospira when compared to standing water (Table 2). Overall, an increase in one unit TDS reduced the chance of finding Leptospira by approximately $1 \%$. However, when evaluating TDS in interaction with the type of water, we observed an increase of approximately $0.05 \%$ in the chance of finding Leptospira in sewage when compared to standing water (Table 2). In addition, Generalized Additive Model (GAM) analysis identified a positive relationship 
between TDS and positivity rate for the TDS interval of $15-300 \mathrm{mg} / \mathrm{L}$ and a negative relationship for the TDS interval of 300-1000 mg/L (Figure 1A).

Table 2. Estimated regression parameters (odds ratio and confidence interval) in the final logistic and parameters (coefficient and confidence interval) in the final linear models on the chance and probability of finding a positive sample and $\log 10$ concentration of Leptospira, respectively. $\left.{ }^{* * *}\right) p<0.01$, $\left.\left.{ }^{* *}\right) p<0.05,{ }^{*}\right) p<0.1$.

\begin{tabular}{ccccc}
\hline Physicochemical Parameters & \multicolumn{2}{c}{ Logistic Model } & \multicolumn{2}{c}{ Linear Model } \\
\hline & Odds Ratio & $\mathbf{9 5 \%}$ CI & Coefficient & $\mathbf{9 5 \% ~ C I ~}$ \\
\hline pH & 1.132 & $0.52-2.47$ & $0.28^{* *}$ & $0.09-0.48$ \\
Turbidity & & & 0.00 & $-0.00-0.00$ \\
TDS & $0.989^{* * *}$ & $0.98-0.99$ & & $-1.34-0.30$ \\
Salinity & $10.097^{*}$ & $1.30-91.07$ & -0.52 & \\
Interaction terms & & & & \\
pH * Water & $0.753^{* *}$ & $0.61-0.93$ & & $-0.15-0.89$ \\
TDS *Water & $1.005^{* * *}$ & $1.00-1.01$ & & \\
Salinity * Water & & &
\end{tabular}
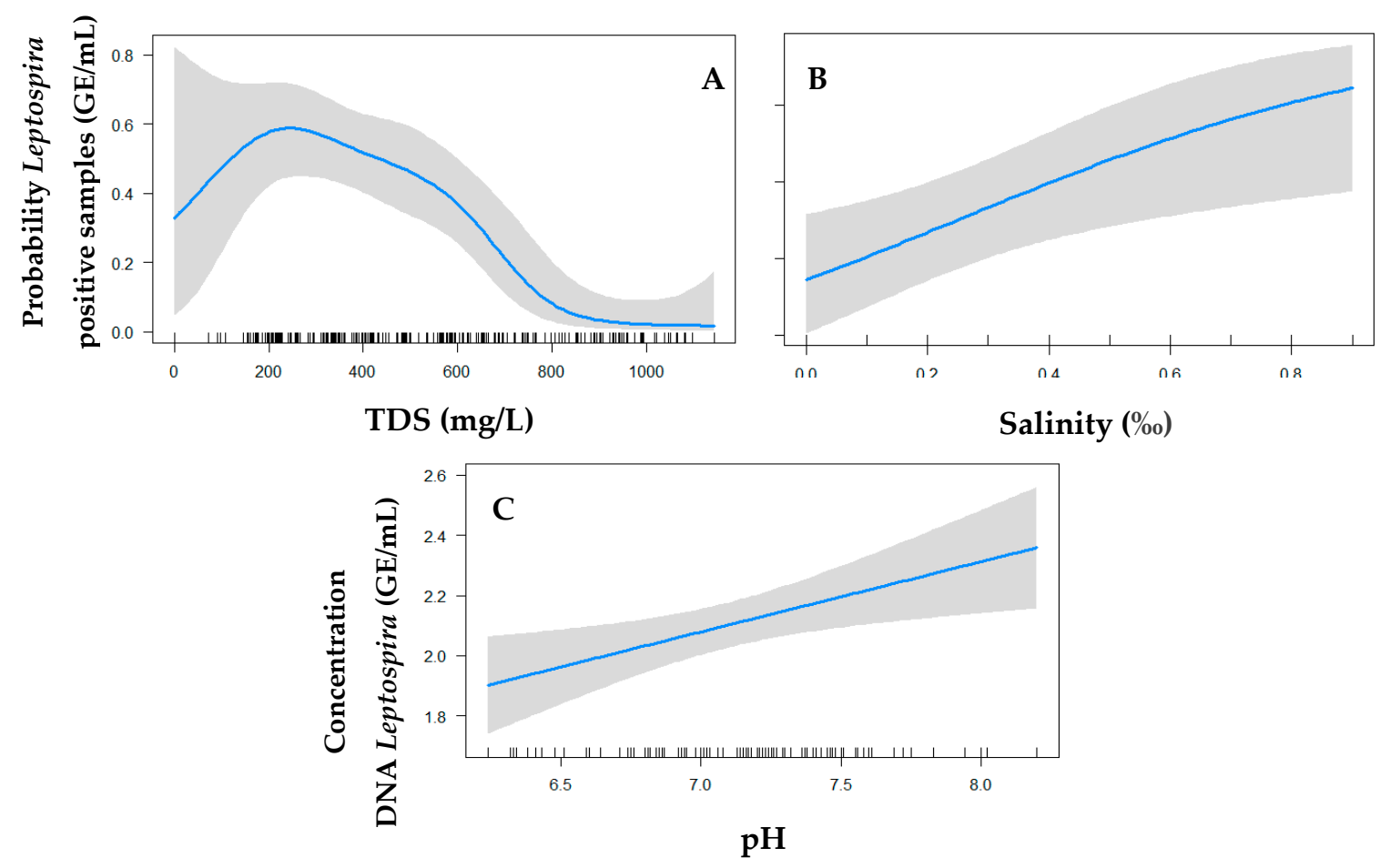

Figure 1. Probability of finding Leptospira positive water samples in the final logistic model according to TDS (A) and salinity (B). Probability of finding Leptospira DNA concentration water samples in the final linear model according to $\mathrm{pH}(\mathbf{C})$. The blue line denotes the predicted chance/probability and the grey area the $95 \%$ confidence interval. Ticks on the $X$-axis denote individual measurements.

In the univariate linear model, we found that the concentration of pathogenic Leptospira was associated with temperature, $\mathrm{pH}$, turbidity, salinity, and electric conductivity $(p<0.2)$. The final linear model for the concentration of pathogenic Leptospira, however, retained only $\mathrm{pH}$ as a significant parameter $(p<0.001)$. Increases in $\mathrm{pH}$ were associated with increased concentrations of pathogenic Leptospira (Figure 1C). Turbidity was important in the adjustment of the final model. 


\section{Discussion}

The physicochemical properties of water have been suggested to be essential for understanding the maintenance of pathogenic Leptospira and consequently environmental transmission. In this study, specific physicochemical characteristics were differentially related to the presence and load of leptospires identified in water samples from an urban slum. Among the parameters analyzed, TDS, salinity, and $\mathrm{pH}$ were associated with Leptospira positivity in aquatic matrices, while only $\mathrm{pH}$ was associated with the pathogen concentration. We also found significant physicochemical differences between sewer and standing water which affected the chances of identifying positive Leptospira samples.

We observed a positive trend between TDS values 0 and $300 \mathrm{mg} / \mathrm{L}$ and Leptospira presence. However, the lower sample size in this subgroup prevented an appropriate statistical evaluation of this trend. The interaction between TDS and type of water with Leptospira positivity rate also supported this trend, as observed by the higher proportion of Leptospira positive samples in sewage water when compared to standing water (Supplementary Table S2). Previous works have proposed that survival of pathogenic Leptospira in water may increase by adhesion of this bacterium to suspended soil particles or aggregation with other microorganisms $[10,19]$. On the other hand, we identified a negative association between TDS values superior to $300 \mathrm{mg} / \mathrm{L}$ and Leptospira presence rate. The reduction of Leptospira prescence rate may be explained by the fact that high concentrations of TDS can be lethal to aquatic organisms, causing osmotic shock [20]. This effect may affect, for exemple, Leptospira's osmoregulatory strength, reflecting on the ability to adapt to the environment [21]. Besides this, the reduction of light penetration in water, a consequence of the excess of soil particles in aquatic bodies, results in reduced photosynthesis capacity in water organisms. In this scenario, a drop in the oxygen supply present in this medium is possible, thus affecting Leptospira's survival, because these bacteria are obligatory aerobic [22].

We found that a $1 \%$ increase in salinity was associated with a tenfold increase in Leptospira positivity rate. These findings corroborate the study by Viau and Boehm (2011) [23], which observed a positive association between Leptospira DNA concentration and salinity rate. However, Khairani-Bejo (2004) found that the duration of Leptospira decreased as the salinity increased, where the organism died in seawater, where the salinity is on average 35\%. Another study showed that, even in a solution with low salt concentration $(0.13 \% \mathrm{NaCl})$, Leptospira's survival can decrease, promoting inhibition of the energetic function of this bacterium [10].

The analysis of the interaction between $\mathrm{pH}$ and water type showed a negative association, and sewage samples with acidic $\mathrm{pH}$ presented a higher chance of detecting the presence of Leptospira when compared to standing water. However, $\mathrm{pH}$ was positively associated with pathogenic Leptospira load. Similarly, previous laboratory studies demonstrate that Leptospira survival improves in alkaline environments $[8,24,25]$. Ideal $\mathrm{pH}$ value for survival is close to neutral [22] and extreme $\mathrm{pH}$ values are lethal for pathogenic leptospires. A previous controlled laboratory study shows that, even under identical conditions, different survival patterns among different serovars are observed. They reported that Leptospira serovar Icterohaemorrhagiae increased their survival time by months at $\mathrm{pH}$ above $7.0[22,24]$. It is known that the $\mathrm{pH}$ of water affects the availability of micronutrients and extreme values can have a toxic effect for some microorganisms [20].

We did not find an association between turbidity and Leptospira concentration. Our results are different from the ones reported by Viau and Boehm (2011) [23], which found a significant correlation between turbidity and the concentration of Leptospira in the river waters in Hawaii. However, the qPCR approach used in Hawaii was not specific for pathogenic Leptospira and detected intermediate and pathogenic species. Alternatively, the relationship between turbidity and or TDS and Leptospira may be related to the phenomena of precipitation, mobilization, and dilution. Pathogenic Leptospira are released by rodents on the soil surface [26,27], where they persist for a prolonged period [28-30]. During heavy rain events, pathogenic Leptospira can be mobilized and resuspended from the soil reservoir along with sediment, directed to open sewers and drainage with runoff and, as a result, increasing turbidity and TDS [23,31]. 
The average water temperature at Pau da Lima was $25^{\circ} \mathrm{C}$, and the values did not vary with the type of water. This is in agreement with a previous laboratory study that showed that a water temperature range between 25 and $30^{\circ} \mathrm{C}$ allows the survival of pathogenic Leptospira [8]. For example, Fontaine et al. 2015 observed the greatest survival rate of Leptospira on days with temperatures of $20^{\circ} \mathrm{C}$ and $30{ }^{\circ} \mathrm{C}$ [32]. One of the limitations of our study was that we did not measure dissolved oxygen in the water samples, which varies with temperature and can be an important parameter for Leptospira survival [33].

\section{Conclusions}

In conclusion, this study provides novel field data indicating a relationship between physicochemical variables (specifically TDS, salinity, and $\mathrm{pH}$ ) and the presence and concentration of pathogenic Leptospira in sewage and standing water in urban slums. Further studies should aim to examine causality and confounding factors not considered in this analysis (i.e., rainfall intensity, presence of animal reservoirs, geographical diversity, etc.). As the presence of this Leptospira in water contributes to leptospirosis in vulnerable communities in developing tropical nations, research on the mechanisms behind Leptospira distribution in the environment may be valuable to inform better public health measures to reduce the burden of the disease.

Supplementary Materials: The following are available online at http://www.mdpi.com/2414-6366/5/3/146/s1, Table S1: Distribution of collected samples, presented by collection period and water type, Table S2: Physicochemical parameters (mean and standard deviation) and concentration of pathogenic Leptospira (geometric mean and count range among positive samples) measured in the standing and sewage water samples collected in Pau da Lima; Table S3: Estimated regression parameters in the bivariate logistic (odds ratio and confidence interval) and linear (coefficient and confidence interval) models on the probability of finding a positive sample and log 10 concentration of Leptospira, respectively. Analysis of the interaction of chemical physical parameters by water type. $\left.{ }^{* * *}\right) p<0.01$, $\left.\left.{ }^{* *}\right) p<0.05,{ }^{*}\right) p<0.1$.

Author Contributions: Conceptualization, D.d.O., V.A.Q., A.C.-M., and F.C., methodology, D.d.O., V.A.Q., A.C.-M., and F.C.; validation, N.N.J., D.d.O., and F.C., formal analysis, N.N.J., M.C., D.d.O., and F.C.; investigation, D.d.O. and F.C.; resources, F.C., M.G.R., A.I.K., J.C.R.A., and L.W.P.; data curation, D.d.O. and N.N.J.; writing-original draft preparation, D.d.O., Y.S.L., and V.A.Q.; writing-review and editing, D.d.O., Y.S.L., F.C., M.G.R., A.C.-M., and N.N.J.; supervision, F.C.; funding acquisition, F.C. All authors have read and agreed to the published version of the manuscript.

Funding: This research received external funding from the Oswaldo Cruz Foundation and Secretariat of Health Surveillance, Brazilian Ministry of Health, the National Institutes of Health (grant numbers R01 AI052473, U01 AI088752, R01 TW009504, R25 TW009338, and R01 AI121207) and from the Wellcome Trust (102330/Z/13/Z).

Acknowledgments: This work could not have been accomplished without the joint collaborative effort of the resident associations, community leaders, and residents which constitute the Urban Health Council of Pau da Lima. We thank Fábio Neves and Luciano Kalabric for their help with statistical analysis and Caio Graco Zeppelini for his help with manuscript proofing.

Conflicts of Interest: The authors declare no conflict of interest. The funders had no role in the design of the study; in the collection, analyses, or interpretation of data; in the writing of the manuscript, or in the decision to publish the results.

\section{References}

1. Torgerson, P.R.; Hagan, J.E.; Costa, F.; Calcagno, J.; Kane, M.; Martinez-Silveira, M.S.; Goris, M.G.; Stein, C.; Ko, A.I.; Abela-Ridder, B. Global Burden of Leptospirosis: Estimated in Terms of Disability Adjusted Life Years. PLoS Negl. Trop. Dis. 2015, 9, e0004122. [CrossRef] [PubMed]

2. Costa, F.; Hagan, J.E.; Calcagno, J.; Kane, M.; Torgerson, P.; Martinez-Silveira, M.S.; Stein, C.; Abela-Ridder, B.; Ko, A.I. Global Morbidity and Mortality of Leptospirosis: A Systematic Review. PLoS Negl. Trop. Dis. 2015, 9, e0003898. [CrossRef] [PubMed]

3. Ko, A.I.; Goarant, C.; Picardeau, M. Leptospira: The dawn of the molecular genetics era for an emerging zoonotic pathogen. Nat. Rev. Microbiol. 2009, 7, 736-747. [CrossRef] [PubMed]

4. McBride, A.J.; Athanazio, D.A.; Reis, M.G.; Ko, A.I. Leptospirosis. Curr. Opin. Infect. Dis. 2005, 18, $376-386$. [CrossRef] 
5. Ganoza, C.A.; Matthias, M.A.; Collins-Richards, D.; Brouwer, K.C.; Cunningham, C.B.; Segura, E.R.; Gilman, R.H.; Gotuzzo, E.; Vinetz, J.M. Determining risk for severe leptospirosis by molecular analysis of environmental surface waters for pathogenic Leptospira. PLoS Med. 2006, 3, e308. [CrossRef]

6. Chang, S.L.; Buckingham, M.; Taylor, M.P. Studies on Leptospira icterohaemorrhagiae; survival in water and sewage; destruction in water by halogen compounds, synthetic detergents, and heat. J. Infect. Dis. 1948, 82, 256-266. [CrossRef]

7. Okazaki, W.; Ringen, L.M. Some effects of various environmental conditions on the survival of Leptospira pomona. Am. J. Vet. Res. 1957, 18, 219-223.

8. Parker, J.; Walker, M. Survival of a pathogenic Leptospira serovar in response to combined in vitro $\mathrm{pH}$ and temperature stresses. Vet. Microbiol. 2011, 152, 146-150. [CrossRef]

9. Petrino, M.G.; Doetsch, R.N. 'Viscotaxis', a new behavioural response of Leptospira interrogans (biflexa) strain B16. J. Gen. Microbiol. 1978, 109, 113-117. [CrossRef]

10. Trueba, G.; Zapata, S.; Madrid, K.; Cullen, P.; Haake, D. Cell aggregation: A mechanism of pathogenic Leptospira to survive in fresh water. Int. Microbiol. 2004, 7, 35-40.

11. Agampodi, S.B.; Dahanayaka, N.J.; Bandaranayaka, A.K.; Perera, M.; Priyankara, S.; Weerawansa, P.; Matthias, M.A.; Vinetz, J.M. Regional differences of leptospirosis in Sri Lanka: Observations from a flood-associated outbreak in 2011. PLoS Negl. Trop. Dis. 2014, 8, e2626. [CrossRef]

12. Ko, A.I.; Galvao Reis, M.; Ribeiro Dourado, C.M.; Johnson, W.D., Jr.; Riley, L.W. Urban epidemic of severe leptospirosis in Brazil. Salvador Leptospirosis Study Group. Lancet 1999, 354, 820-825. [CrossRef]

13. Trevejo, R.T.; Rigau-Perez, J.G.; Ashford, D.A.; McClure, E.M.; Jarquin-Gonzalez, C.; Amador, J.J.; de los Reyes, J.O.; Gonzalez, A.; Zaki, S.R.; Shieh, W.J.; et al. Epidemic leptospirosis associated with pulmonary hemorrhage-Nicaragua, 1995. J. Infect. Dis. 1998, 178, 1457-1463. [CrossRef] [PubMed]

14. Corburn, J.; Riley, L. Slum Health: From the Cell to the Street, 1st ed.; University of California Press: Berkeley, CA, USA, 2016.

15. Hagan, J.E.; Moraga, P.; Costa, F.; Capian, N.; Ribeiro, G.S.; Wunder, E.A., Jr.; Felzemburgh, R.D.; Reis, R.B.; Nery, N.; Santana, F.S.; et al. Spatiotemporal Determinants of Urban Leptospirosis Transmission: Four-Year Prospective Cohort Study of Slum Residents in Brazil. PLoS Negl. Trop. Dis. 2016, 10, e0004275. [CrossRef] [PubMed]

16. Casanovas-Massana, A.; Costa, F.; Riediger, I.N.; Cunha, M.; de Oliveira, D.; Mota, D.C.; Sousa, E.; Querino, V.A.; Nery, N., Jr.; Reis, M.G.; et al. Spatial and temporal dynamics of pathogenic Leptospira in surface waters from the urban slum environment. Water Res. 2018, 130, 176-184. [CrossRef]

17. American Public Health Association (APHA). Standard Method for Examination of Water and Wastewater, 21th ed.; APHA, Ed.; APHA: Washington, DC, USA, 2005.

18. Allaire, J. RStudio: Integrated Development Environment for R; RStudio Team: Boston, MA, USA, 2012; p. 394.

19. Kumar, K.V.; Lall, C.; Raj, R.V.; Vedhagiri, K.; Vijayachari, P. Coexistence and survival of pathogenic leptospires by formation of biofilm with Azospirillum. FEMS Microbiol. Ecol. 2015, 91. [CrossRef]

20. Agoro, M.A.; Okoh, O.O.; Adefisoye, M.A.; Okoh, A.I. Physicochemical Properties of Wastewater in Three Typical South African Sewage Works. Pol. J. Environ. Stud. 2018, 27, 491-499. [CrossRef]

21. Matsunaga, J.; Lo, M.; Bulach, D.M.; Zuerner, R.L.; Adler, B.; Haake, D.A. Response of Leptospira interrogans to physiologic osmolarity: Relevance in signaling the environment-to-host transition. Infect. Immun. 2007, 75, 2864-2874. [CrossRef]

22. Faine, S. Leptospira and Leptospirosis; CRC Press Inc.: Boca Raton, FL, USA, 1994.

23. Viau, E.J.; Boehm, A.B. Quantitative PCR-based detection of pathogenic Leptospira in Hawai'ian coastal streams. J. Water Health 2011, 9, 637-646. [CrossRef]

24. Smith, C.E.; Turner, L.H. The effect of $\mathrm{pH}$ on the survival of leptospires in water. Bull. World Health Organ. 1961, 24, 35-43.

25. Smith, D.J.; Self, H.R. Observations on the survival of Leptospira australis A in soil and water. Epidemiol. Infect. 1955, 53, 436-444. [CrossRef]

26. Costa, F.; Wunder, E.A., Jr.; De Oliveira, D.; Bisht, V.; Rodrigues, G.; Reis, M.G.; Ko, A.I.; Begon, M.; Childs, J.E. Patterns in Leptospira Shedding in Norway Rats (Rattus norvegicus) from Brazilian Slum Communities at High Risk of Disease Transmission. PLoS Negl. Trop. Dis. 2015, 9, e0003819. [CrossRef] [PubMed] 
27. Schneider, A.G.; Casanovas-Massana, A.; Hacker, K.P.; Wunder, E.A., Jr.; Begon, M.; Reis, M.G.; Childs, J.E.; Costa, F.; Lindow, J.C.; Ko, A.I. Quantification of pathogenic Leptospira in the soils of a Brazilian urban slum. PLoS Negl. Trop. Dis. 2018, 12, e0006415. [CrossRef]

28. Casanovas-Massana, A.; Pedra, G.G.; Wunder, E.A., Jr.; Diggle, P.J.; Begon, M.; Ko, A.I. Quantitative survival of Leptospira interrogans in soil and water microcosms. Appl. Environ. Microbiol. 2018. [CrossRef]

29. Khairani-Bejos, S.; Bahaman, A.R.; Zamri-Saad, M.; Mutalib, A.R. The survival of Leptospira interrogans serovar hardjo in the Malaysian Environment. J. Anim. Vet. Adv. 2004, 3, 123-129.

30. Thibeaux, R.; Geroult, S.; Benezech, C.; Chabaud, S.; Soupé-Gilbert, M.-E.; Girault, D.; Bierque, E.; Goarant, C. Seeking the environmental source of Leptospirosis reveals durable bacterial viability in river soils. PLoS Negl. Trop. Dis. 2017, 11, e0005414. [CrossRef]

31. Martín-Díaz, J.; García-Aljaro, C.; Pascual-Benito, M.; Galofré, B.; Blanch, A.R.; Lucena, F. Microcosms for evaluating microbial indicator persistence and mobilization in fluvial sediments during rainfall events. Water Res. 2017, 123, 623-631. [CrossRef]

32. Andre-Fontaine, G.; Aviat, F.; Fau-Thorin, C.; Thorin, C. Waterborne Leptospirosis: Survival and Preservation of the Virulence of Pathogenic Leptospira spp. in Fresh Water. Curr. Microbiol. 2015, 71, 136-142. [CrossRef] [PubMed]

33. Tchobanoglous, G.; Burton, F.L.; Stensel, H.D. Metcalf \& Eddy Wastewater Engineering: Treatment and Reuse, 4th ed.; McGraw-Hill: Boston, MA, USA, 2003.

(C) 2020 by the authors. Licensee MDPI, Basel, Switzerland. This article is an open access article distributed under the terms and conditions of the Creative Commons Attribution (CC BY) license (http://creativecommons.org/licenses/by/4.0/). 